\title{
Characteristics of Silicon Dioxide Particles in PCVD Synthesizing Silica Glass Process
}

\author{
Yuancheng Sun, Xuefu Song, Xiurong Du, Xiaoqiang Zhang, and Hui Wang
}

China Building Materials Academy, Beijing 100024, China

Correspondence should be addressed to Yuancheng Sun; sunyuancheng@cbmamail.com.cn

Received 8 November 2015; Revised 26 January 2016; Accepted 27 January 2016

Academic Editor: Enkeleda Dervishi

Copyright ( 2016 Yuancheng Sun et al. This is an open access article distributed under the Creative Commons Attribution License, which permits unrestricted use, distribution, and reproduction in any medium, provided the original work is properly cited.

\begin{abstract}
$\mathrm{SiO}_{2}$ nanoparticles in PCVD process were investigated by SEM, TEM, and optical emission spectra (OES). There are large spherical $\mathrm{SiO}_{2}$ particles with diameter of $50-200 \mathrm{~nm}$ and more small particles about 10-50 nm in PCVD process. Size of $\mathrm{SiO}_{2}$ particles is influenced by distance and feeding speed but not electron temperature. The amount of large spherical $\mathrm{SiO}_{2}$ particles decreases with the increase of distance and decrease of feeding speed due to lower concentration. In addition, the evolution of $\mathrm{SiO}_{2} \mathrm{particles} \mathrm{was}$ inferred from the experimental results.
\end{abstract}

\section{Introduction}

The technology of plasma chemical vapor deposition (PCVD) [1] synthesizing silica glass uses atmospheric pressure high frequency induction plasma as heat source and high purity silicon tetrachloride as raw material. Silica glass synthesized by this method is the purest man-made bulk silica glass [2] (metallic impurities $<1 \mathrm{ppm}, \mathrm{OH}$-groups $<1 \mathrm{ppm}$ ) due to unpolluted and water-free heat source and raw material. It is the key material in inertial navigation and optical field due to its high purity and unbroken structural network.

Quality of silica glass is mostly decided by the preparation process. The stage of $\mathrm{SiO}_{2}$ nanoparticles forming, colliding, aggregating, and depositing onto substrate is the key step in PCVD process, and size and morphology of the particles ultimately influence quality of silica glass [3]. So investigation of $\mathrm{SiO}_{2}$ particles in PCVD process can help us to improve quality of silica glass and depositing efficiency and reduce consumption of energy and raw materials. However, little research on it has been reported until now. Many studies have been carried out on $\mathrm{SiO}_{2}$ nanoparticles in other flames. Ulrich and coworkers [4-7] studied synthesis of $\mathrm{SiO}_{2}$ nanopowders in hydrocarbon flames and related particle size to residence time and precursor concentration and process temperature. Wang et al. [8] studied $\mathrm{SiO}_{2}$ particles in oxyhydrogen flame CVD synthesizing silica glass and observed shrinkage of particle along the flame at low precursor concentration, which they attributed to evaporation, and few changes on its characteristics at high concentration. Tandon and Boek [9] presented models to estimate $\mathrm{SiO}_{2}$ soot number density and mean size at different locations in oxyhydrogen flame.

The objective of the present study is to investigate characteristics of $\mathrm{SiO}_{2}$ particles in PCVD and understand evolution of $\mathrm{SiO}_{2}$ particles in plasma flame. Input power of plasma generator has been changed to get different flame temperature and feeding speed has been changed to get different concentration. Characteristics of $\mathrm{SiO}_{2}$ particles at different distance from exit of plasma torch have been discussed to investigate evolution of $\mathrm{SiO}_{2}$ particles. At last, the evolution of $\mathrm{SiO}_{2}$ particles in PCVD process will be discussed.

\section{Experimental}

Plasma flame was generated by high frequency generator with rated power of $100 \mathrm{~kW}$ and frequency of $4.6 \mathrm{MHz}$. Ionizing gas and protecting gas were both filtered dry air. Optical emission spectra of the plasma flame in the region of 200-1077 nm were recorded by 7 channels' AvaSpec-ULS3648 fiber spectrometer with best resolution of $0.05 \mathrm{~nm}$. Electron temperature $T_{e}$ was calculated by Boltzmann plot method using $\mathrm{N}$ spectra $[10,11]$. Pure oxygen carried silicon tetrachloride was injected into the plasma flame and formed 
$\mathrm{SiO}_{2}$ particles. Silica glass sampler was swept past the flame quickly and $\mathrm{SiO}_{2}$ particles deposited onto the sampler. Morphology of the $\mathrm{SiO}_{2}$ particles was investigated by Hitachi SU8010 scanning electron microscope and Hitachi H-800 transmission electron microscope.

\section{Results and Discussions}

3.1. Formation of $\mathrm{SiO}_{2}$ Particles. Because feeding gas in PCVD process is oxygen and ionization gas of plasma is air, only oxidation reaction of silicon tetrachloride takes place in the plasma flame. The chemical reaction equation is as follows:

$$
\mathrm{SiCl}_{4}+\mathrm{O}_{2}=\mathrm{SiO}_{2}+2 \mathrm{Cl}_{2}
$$

Silicon tetrachloride is ionized immediately when it goes into plasma flame carried by oxygen. The change of state of plasma results in the change of optical emission spectrum. Figure 1 shows the optical emission spectra of the plasma flame at the distance of $9 \mathrm{~cm}$ before and after feeding, when the input power of plasma generator was $80 \mathrm{~kW}$ and feeding speed of silicon tetrachloride was $10 \mathrm{~g} / \mathrm{min}$. It can be seen that strong $\mathrm{Si}$ and $\mathrm{Cl}$ lines appear after feeding. Particularly, the region of 540-665 $\mathrm{nm}$ containing $\mathrm{Si}, \mathrm{Cl}, \mathrm{O}$, and $\mathrm{N}$ lines has significant difference after feeding. As a result, optical emission spectrum of this region will be mainly discussed. Electron temperature $T_{e}$ decreased from $15245 \mathrm{~K}$ to $9666 \mathrm{~K}$ after feeding, which demonstrates that heavy ions of silicon tetrachloride and oxygen absorb quantity energy of electrons. Even so, the temperature is much higher than melting point of $\mathrm{SiO}_{2}$ and enough to melt it. So $\mathrm{SiO}_{2}$ particles are in liquid state in plasma flame.

$\mathrm{SiO}_{2}$ particles at $9 \mathrm{~cm}$ were sampled, and SEM and TEM morphology were observed, which are shown in Figures 2 and 3. The SEM morphology shows that most $\mathrm{SiO}_{2}$ particles are "tiny" spherical ones with diameter of 10-50 nm, and few abnormal "large" spherical particles about 50-200 $\mathrm{nm}$ in diameter (encircled), which are less than 1 percent in quantity. The TEM morphology of Figure 3(a) also shows that most particles are smaller than $50 \mathrm{~nm}$ and some of them are larger than $50 \mathrm{~nm}$. Figure 3(b) shows particles with diameter of about $200 \mathrm{~nm}$, but it takes effort to find them through TEM. In addition, it is hard to observe the surface morphology of $\mathrm{SiO}_{2}$ particles by TEM. As a result, morphology of $\mathrm{SiO}_{2}$ particles will be characterized by SEM in the following study.

3.2. Influence of Input Power. State of plasma is influenced greatly by input power of plasma generator, and higher input power results in higher electron temperature. $\mathrm{SiO}_{2}$ particles were investigated when input power is $80 \mathrm{~kW}, 85 \mathrm{~kW}$, and $90 \mathrm{~kW}$, respectively, when the feeding speed of silicon tetrachloride was $10 \mathrm{~g} / \mathrm{min}$ and sampling distance was $9 \mathrm{~cm}$. Optical emission spectra of the plasma flame at different input power are shown in Figure 4. It can be seen that the spectrum is stronger slightly when input power increases. Electron temperatures $T_{e}$ calculated are $9666 \mathrm{~K}, 10054 \mathrm{~K}$, and $12875 \mathrm{~K}$ at $80 \mathrm{~kW}, 85 \mathrm{~kW}$, and $90 \mathrm{~kW}$, respectively. The electron temperature increases dramatically when input power increases.
Figure 5 shows the SEM morphology of $\mathrm{SiO}_{2}$ particles at $85 \mathrm{~kW}$ and $90 \mathrm{~kW}$. Compared with Figure 2, which was at the condition of $80 \mathrm{~kW}$, most $\mathrm{SiO}_{2}$ particles in the three conditions are smaller than $50 \mathrm{~nm}$, and only several particles larger than $50 \mathrm{~nm}$ can be observed (encircled), which are less than 1 percent in quantity. Therefore, electron temperature does not affect the size of $\mathrm{SiO}_{2}$ particles.

3.3. Influence of Distance. In order to investigate evolution of $\mathrm{SiO}_{2}$ particles in plasma flame, $\mathrm{SiO}_{2}$ particles at distances of $8 \mathrm{~cm}, 9 \mathrm{~cm}$, and $10 \mathrm{~cm}$ from exit of plasma torch were sampled when input power was $80 \mathrm{~kW}$ and feeding speed of silicon tetrachloride was $10 \mathrm{~g} / \mathrm{min}$. SEM morphologies of $\mathrm{SiO}_{2}$ particles at the distances of $8 \mathrm{~cm}$ and $10 \mathrm{~cm}$ are shown in Figure 6, and that of $9 \mathrm{~cm}$ can be seen in Figure 2. Figure 6(a) shows that about 50 percent of $\mathrm{SiO}_{2}$ particles are larger than $50 \mathrm{~nm}$ at $8 \mathrm{~cm}$, and near 10 percent of them are larger than $100 \mathrm{~nm}$. When the distance increases to $9 \mathrm{~cm}$ (Figure 2), less than 1 percent of the particles are larger than $50 \mathrm{~nm}$. While at the distance of $10 \mathrm{~cm}$ showed in Figure 6(b), no $\mathrm{SiO}_{2}$ particles larger than $50 \mathrm{~nm}$ can be observed. Therefore, the amount of large $\mathrm{SiO}_{2}$ particles decreases with the increase of distance.

Optical emission spectra of the plasma flame at different distance are shown in Figure 7. It can be seen that optical emission spectrum at $9 \mathrm{~cm}$ is the strongest, and spectrum at $10 \mathrm{~cm}$ is stronger slightly than that of $8 \mathrm{~cm}$. And electron temperature $T_{e}$ at the distance of $8 \mathrm{~cm}, 9 \mathrm{~cm}$, and $10 \mathrm{~cm}$ is $7904 \mathrm{~K}, 9666 \mathrm{~K}$, and $9445 \mathrm{~K}$, respectively. Because inductively coupled plasma has a hollow structure and the distance of $8 \mathrm{~cm}$ is near core of plasma, the temperature at $9 \mathrm{~cm}$ is higher than that of $8 \mathrm{~cm}$. Temperature decreases at the tail of plasma flame, so the temperature at $10 \mathrm{~cm}$ is lower than that of $9 \mathrm{~cm}$.

The results show that when the distance increases, the electron temperature first increases and then decreases, while the diameter of $\mathrm{SiO}_{2}$ particles always decreases. So the diameter of $\mathrm{SiO}_{2}$ particles is influenced by distance, but not electron temperature, which confirms the conclusion of former part.

3.4. Influence of Feeding Speed. Feeding speeds of silicon tetrachloride were set as $10 \mathrm{~g} / \mathrm{min}, 12 \mathrm{~g} / \mathrm{min}$, and $14 \mathrm{~g} / \mathrm{min}$, respectively, and $\mathrm{SiO}_{2}$ particles at distance of $9 \mathrm{~cm}$ were sampled. SEM morphology of $12 \mathrm{~g} / \mathrm{min}$ and $14 \mathrm{~g} / \mathrm{min}$ is shown in Figure 8, and Figure 2 shows the SEM morphology at the speed of $10 \mathrm{~g} / \mathrm{min}$. It is clear that with the increase of feeding speed $\mathrm{SiO}_{2}$ particles become bigger, and the amount of large spherical $\mathrm{SiO}_{2}$ particles increases. Few large spherical $\mathrm{SiO}_{2}$ particles can be seen at $10 \mathrm{~g} / \mathrm{min}$. When the feeding speed increases to $12 \mathrm{~g} / \mathrm{min}$, about 30 percent of the particles are larger than $50 \mathrm{~nm}$, while at the feeding speed of $14 \mathrm{~g} / \mathrm{min}$, most $\mathrm{SiO}_{2}$ particles are larger than $50 \mathrm{~nm}$. Optical emission spectra of the plasma flame at the three conditions are shown in Figure 9, which shows that optical emission lines decrease slightly with increase of feeding speed. Electron temperature $T_{e}$ at the feeding speed of $10 \mathrm{~g} / \mathrm{min}, 12 \mathrm{~g} / \mathrm{min}$, and $14 \mathrm{~g} / \mathrm{min}$ is $9666 \mathrm{~K}, 9648 \mathrm{~K}$, and $9616 \mathrm{~K}$, respectively. $T_{e}$ decreases slightly with the increase of feeding speed.

Now we can infer the evolution of $\mathrm{SiO}_{2}$ particles from the experimental results. $\mathrm{Si}$ is dissociated immediately by plasma after silicon tetrachloride was injected into it. Free Si 


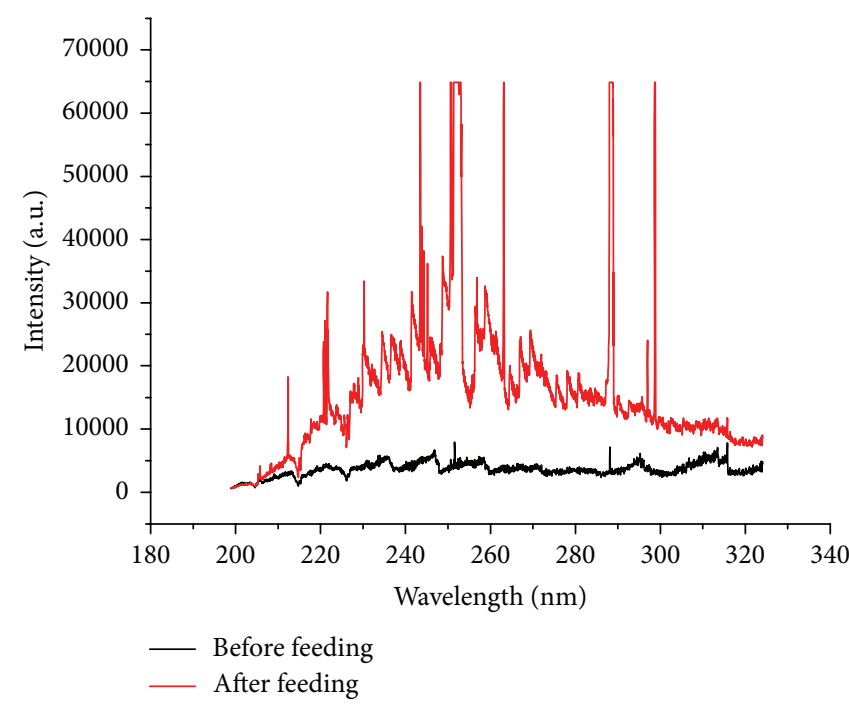

(a) $200-325 \mathrm{~nm}$

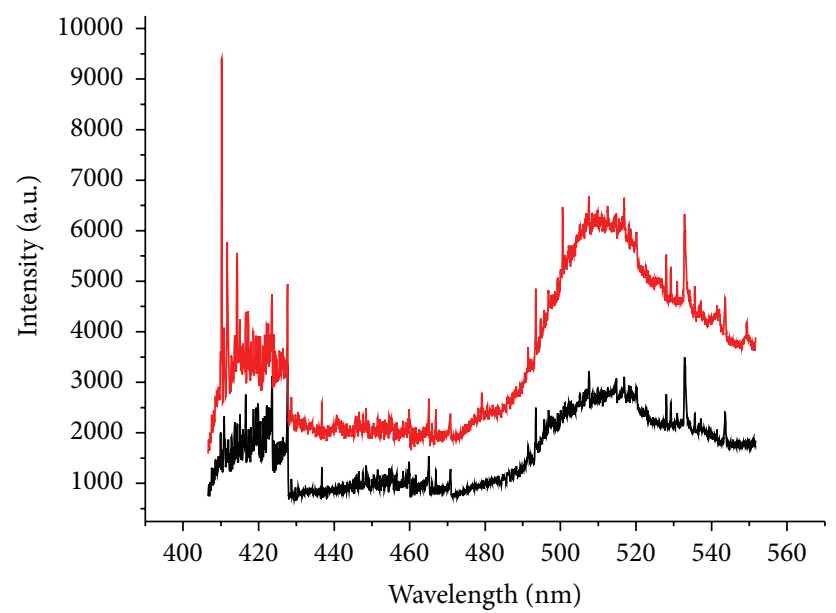

_ Before feeding

_ After feeding

(c) $406-550 \mathrm{~nm}$

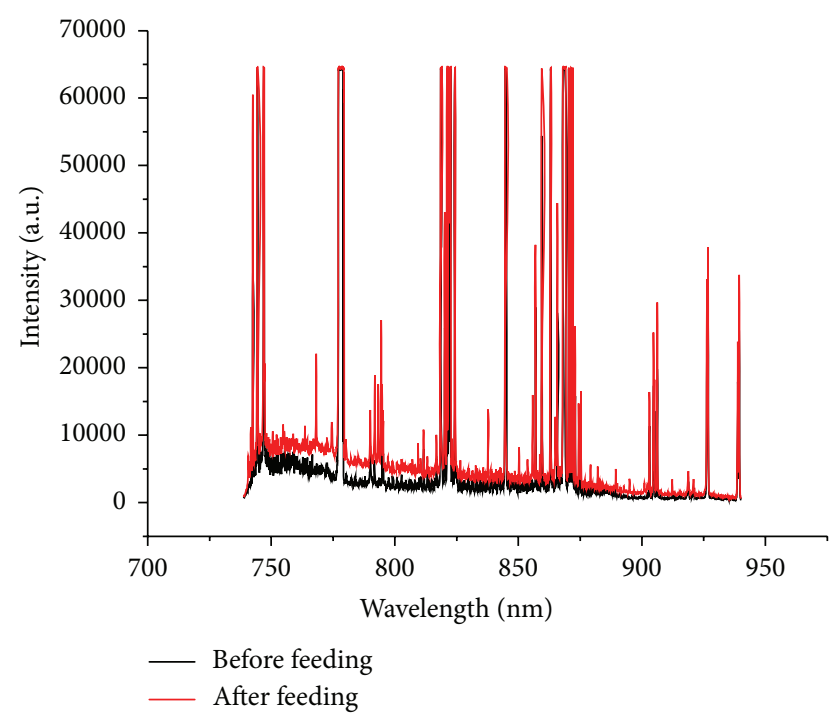

(e) $738-940 \mathrm{~nm}$

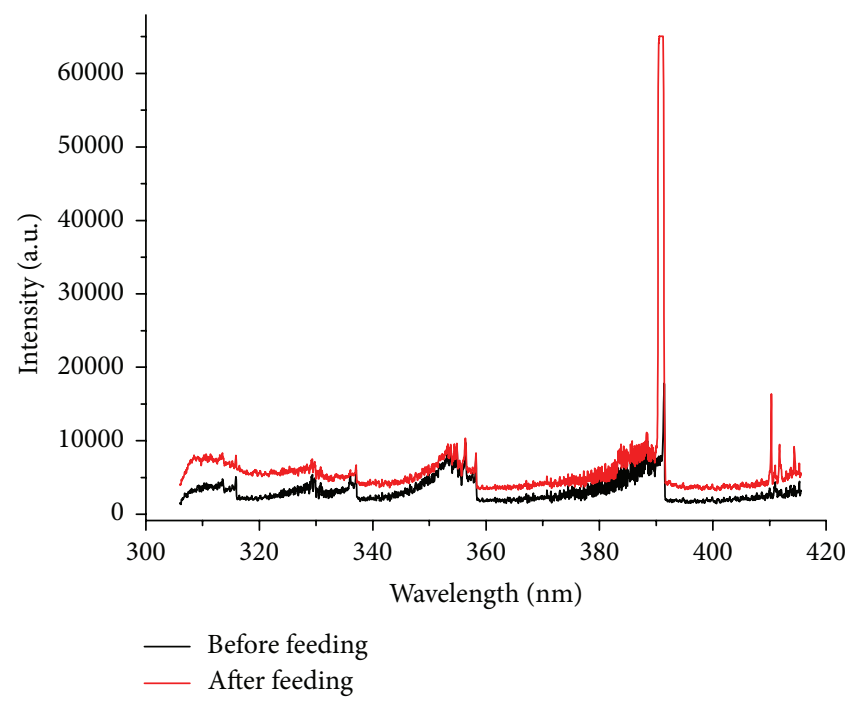

(b) $305-415 \mathrm{~nm}$

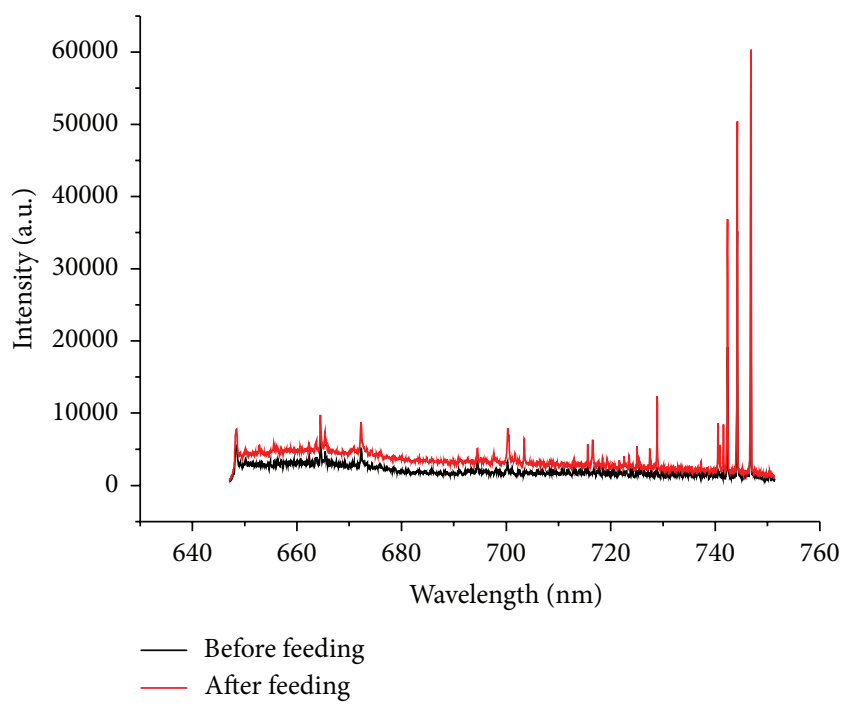

(d) $647-751 \mathrm{~nm}$

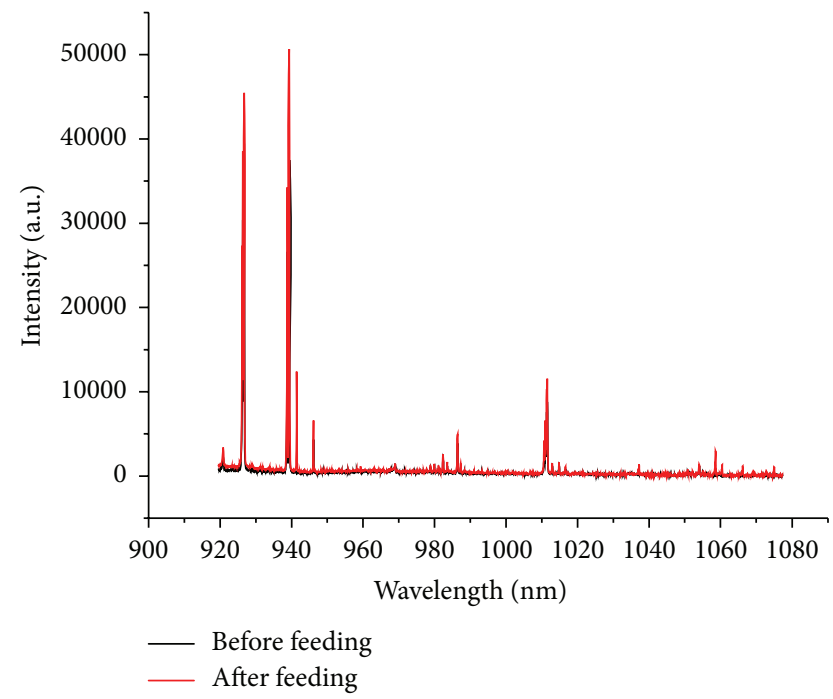

(f) $919-1077 \mathrm{~nm}$

Figure 1: Continued. 


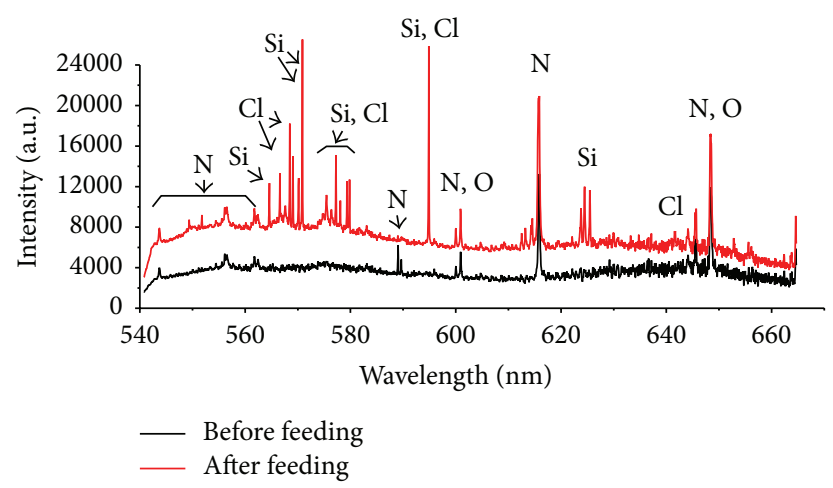

(g) $540-665 \mathrm{~nm}$

FIGURE 1: Optical emission spectra of the plasma flame before and after feeding.

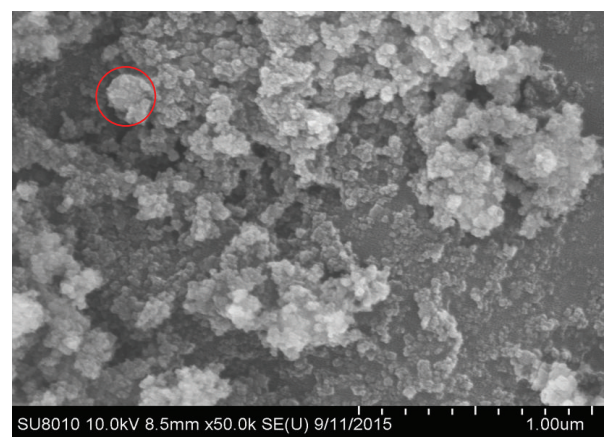

FIGURE 2: SEM morphology of $\mathrm{SiO}_{2}$ particles $(80 \mathrm{~kW}, 10 \mathrm{~g} / \mathrm{min}$, and $9 \mathrm{~cm}$; encircled particle is particle larger than $50 \mathrm{~nm})$.

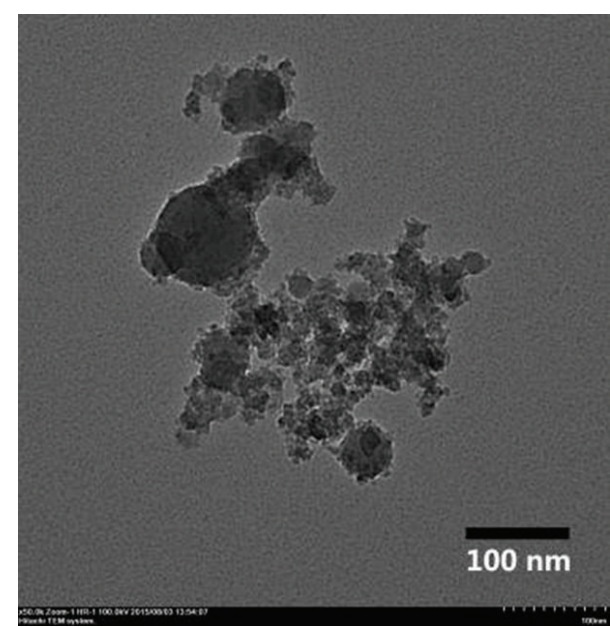

(a) Common morphology

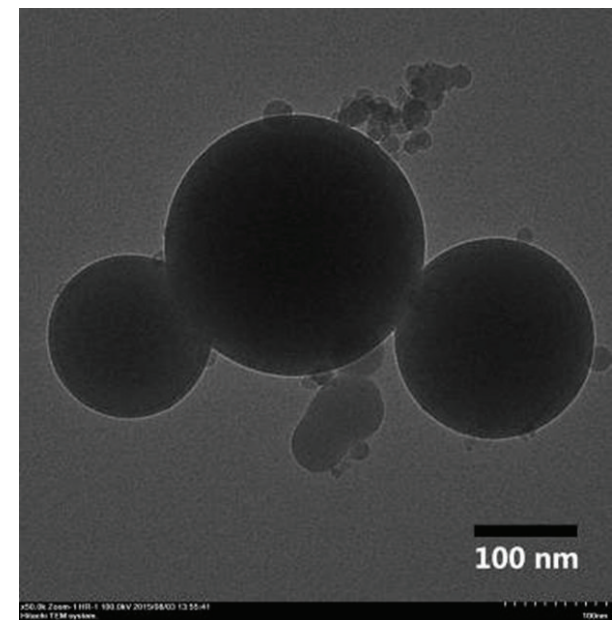

(b) Large particles hard to find

FIgURE 3: TEM morphology of $\mathrm{SiO}_{2}$ particles $(80 \mathrm{~kW}, 10 \mathrm{~g} / \mathrm{min}$, and $9 \mathrm{~cm})$.

atoms will be combined with $\mathrm{O}$ to form a large amount of tiny $\mathrm{SiO}_{2}$ particles, which are in liquid state and moving in high speed due to high temperature of plasma. The tiny $\mathrm{SiO}_{2}$ particles can collide and aggregate with each other to form larger particles. At the same time, large $\mathrm{SiO}_{2}$ particles can get smaller due to evaporation. $\mathrm{SiO}_{2}$ particles have stronger probability to form large ones when the concentration is high. As a result, there are more large $\mathrm{SiO}_{2}$ particles at higher feeding speed. In addition, when the distance from exit of plasma torch is longer, $\mathrm{SiO}_{2}$ will be mixed with fluid of plasma and the concentration will decrease, so the amount of large $\mathrm{SiO}_{2}$ particles will decrease. 


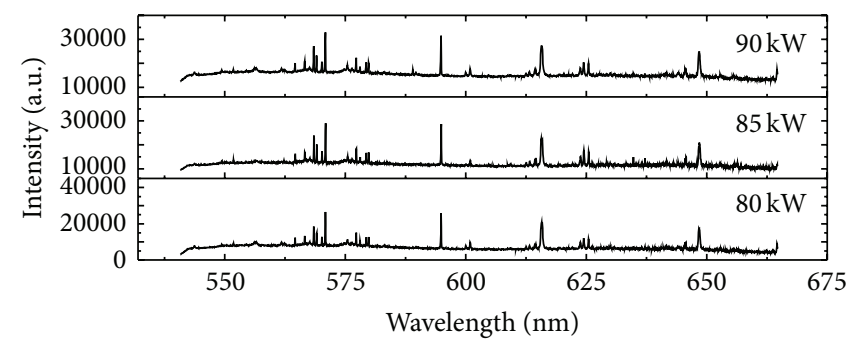

FIGURE 4: Optical emission spectra of the plasma flame at different input power.

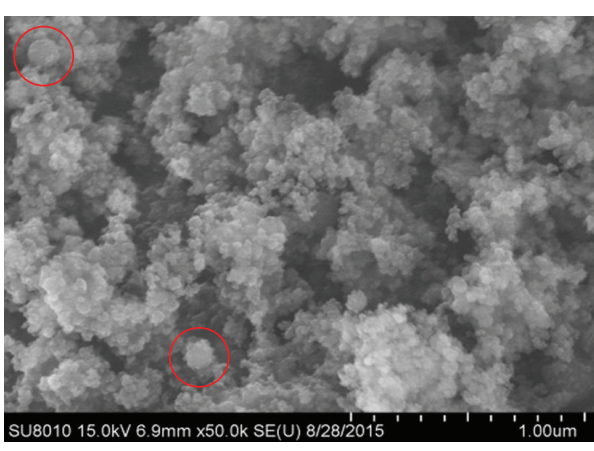

(a) $85 \mathrm{~kW}$

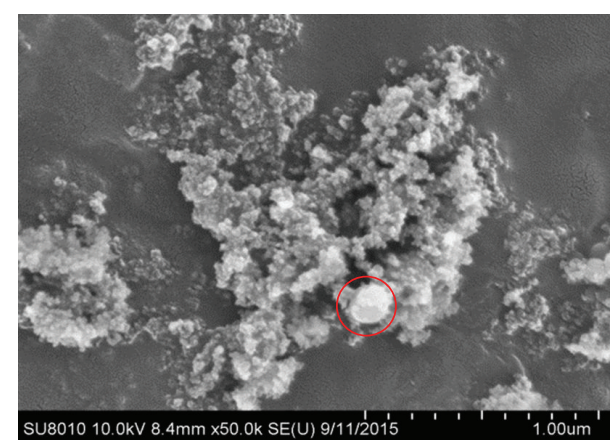

(b) $90 \mathrm{~kW}$

Figure 5: SEM morphology of $\mathrm{SiO}_{2}$ particles at different input power $(10 \mathrm{~g} / \mathrm{min}, 9 \mathrm{~cm}$; encircled particles are particles larger than $50 \mathrm{~nm})$.

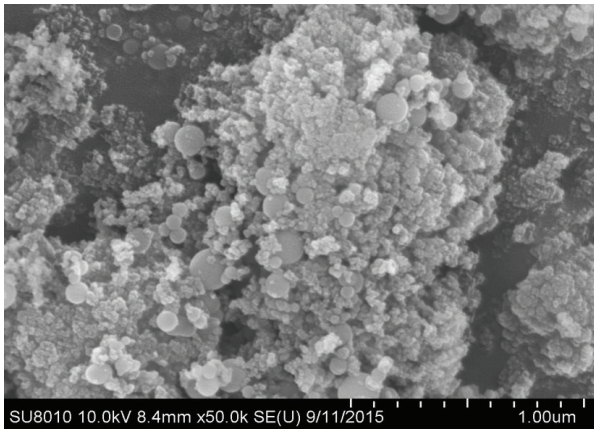

(a) $8 \mathrm{~cm}$

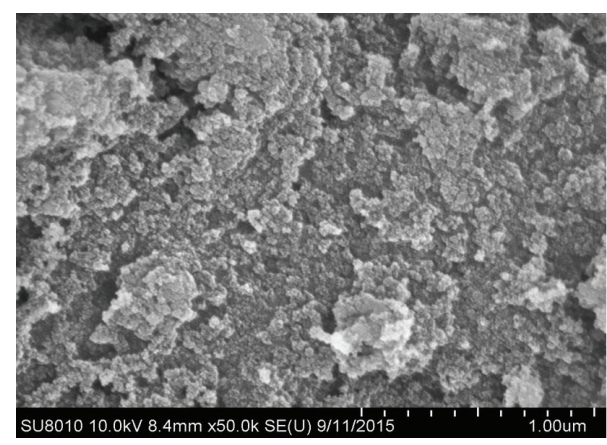

(b) $10 \mathrm{~cm}$

FIGURE 6: SEM morphology of $\mathrm{SiO}_{2}$ particles at different distance $(80 \mathrm{~kW}, 10 \mathrm{~g} / \mathrm{min})$.

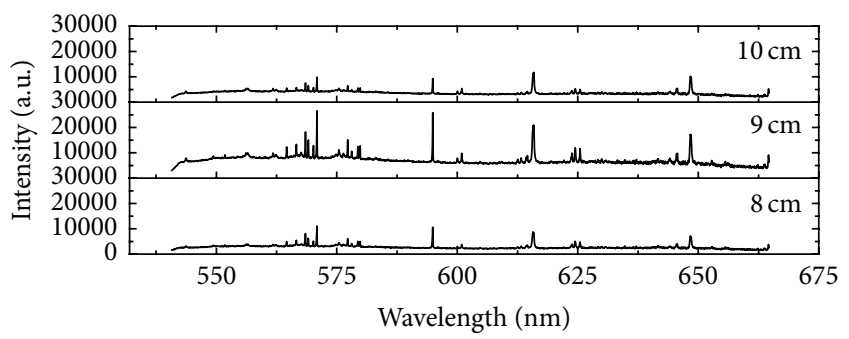

FIGURE 7: Optical emission spectra of the plasma flame at different distance.

\section{Conclusions}

There are large spherical $\mathrm{SiO}_{2}$ particles with diameter of $50-$ $200 \mathrm{~nm}$ and more small particles about $10-50 \mathrm{~nm}$ in PCVD process. Size of $\mathrm{SiO}_{2}$ particles is decided by $\mathrm{SiO}_{2}$ concentration, which influences aggregation and division of particles. The amount of large spherical $\mathrm{SiO}_{2}$ particles decreases with the increase of distance and decrease of feeding speed due to lower concentration. Electron temperature is high enough for melting of $\mathrm{SiO}_{2}$ particle and has no effect on its size. It is generally accepted that larger $\mathrm{SiO}_{2}$ particles have larger momentum and have more chance to pass through sheath and deposit on substrate in PCVD. Therefore, increasing feeding speed and shortening the distance of plasma torch and substrate can improve depositing efficiency, while changing input power of plasma generator has no effect on it. But higher temperature is beneficial for melting $\mathrm{SiO}_{2}$ particles deposited on substrate. In order to produce high quality silica glass, further studies should be carried on to find optimal 


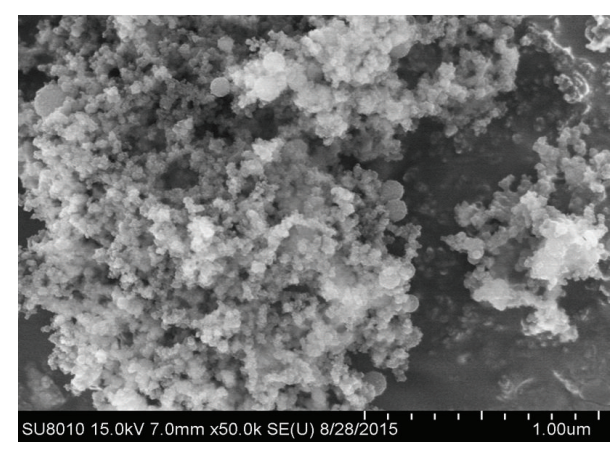

(a) $12 \mathrm{~g} / \mathrm{min}$

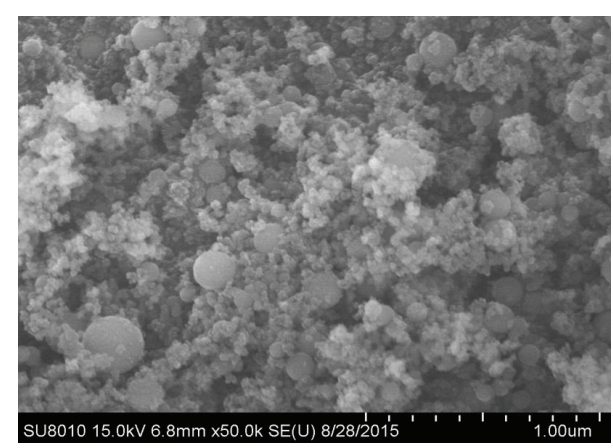

(b) $14 \mathrm{~g} / \mathrm{min}$

FIGURE 8: SEM morphology of $\mathrm{SiO}_{2}$ particles at different feeding speed $(80 \mathrm{~kW}, 9 \mathrm{~cm})$.

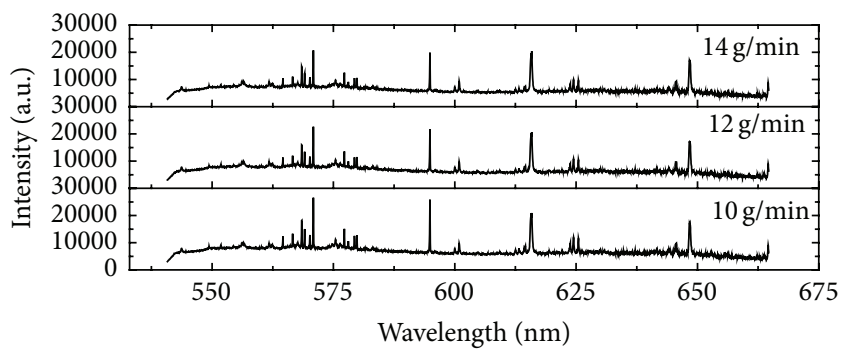

Figure 9: Optical emission spectra of the plasma flame at different feeding speed.

combination of input power and depositing distance and feeding speed.

\section{Conflict of Interests}

The authors declare that there is no conflict of interests regarding the publication of this paper.

\section{Acknowledgment}

The authors would like to express their gratitude to the National Key Technology Research and Development Program of the Ministry of Science and Technology of China (2013BAE03B01) and Youngsters Foundation of CBMA (2013-YT-91), for their financial contribution to this study.

\section{References}

[1] X. Song, Y. Sun, H. Zhong, H. Wang, and Z. Gu, "Synthesis of silica glass by plasma chemical vapor deposition method," Journal of the Chinese Ceramic Society, vol. 36, no. 4, pp. 531534, 2008.

[2] R. Brückner, "Properties and structure of vitreous silica. I," Journal of Non-Crystalline Solids, vol. 5, no. 2, pp. 123-175, 1970.

[3] M. Sui, Y. Sun, X. Song, and H. Wang, "Research of structural homogeneity of CVD synthetic silica glass," Journal of Wuhan University of Technology, vol. 32, no. 22, pp. 106-110, 2010, http:// en.cnki.com.cn/Article_en/CJFDTOTAL-WHGY201022029.htm.
[4] G. D. Ulrich, "Theory of particle formation and growth in oxide synthesis flames," Combustion Science and Technology, vol. 4, no. 1, pp. 47-57, 1971.

[5] G. D. Ulrich, A. B. Milnes, and N. S. Subramanian, "Particle growth in flames. II: experimental results for silica particles," Combustion Science and Technology, vol. 14, no. 4-6, pp. 243249, 1976.

[6] G. D. Ulrich and N. S. Subramanian, "Coalescence as a rate-controlling process," Combustion Science and Technology, vol. 17, no. 3-4, pp. 119-126, 1977.

[7] G. D. Ulrich and J. W. Rieh, "Aggregation and growth of submicron oxide particles in flames," Journal of Colloid And Interface Science, vol. 87, no. 1, pp. 257-265, 1982.

[8] L. Wang, C. Rao, and Z. Gu, "Effects of flame temperature and $\mathrm{SiCl}_{4}$ concentration on particle characteristics for synthetic silica glass," Journal Wuhan University of Technology, Materials Science Edition, vol. 25, no. 3, pp. 419-422, 2010.

[9] P. Tandon and H. Boek, "Experimental and theoretical studies of flame hydrolysis deposition process for making glasses for optical planar devices," Journal of Non-Crystalline Solids, vol. 317, no. 3, pp. 275-289, 2003.

[10] J. Cooper, "Plasma spectroscopy," Reports on Progress in Physics, vol. 29, no. 1, pp. 35-130, 1966.

[11] M. Meyyappan, "A review of plasma enhanced chemical vapour deposition of carbon nanotubes," Journal of Physics D: Applied Physics, vol. 42, no. 21, Article ID 213001, 2009. 

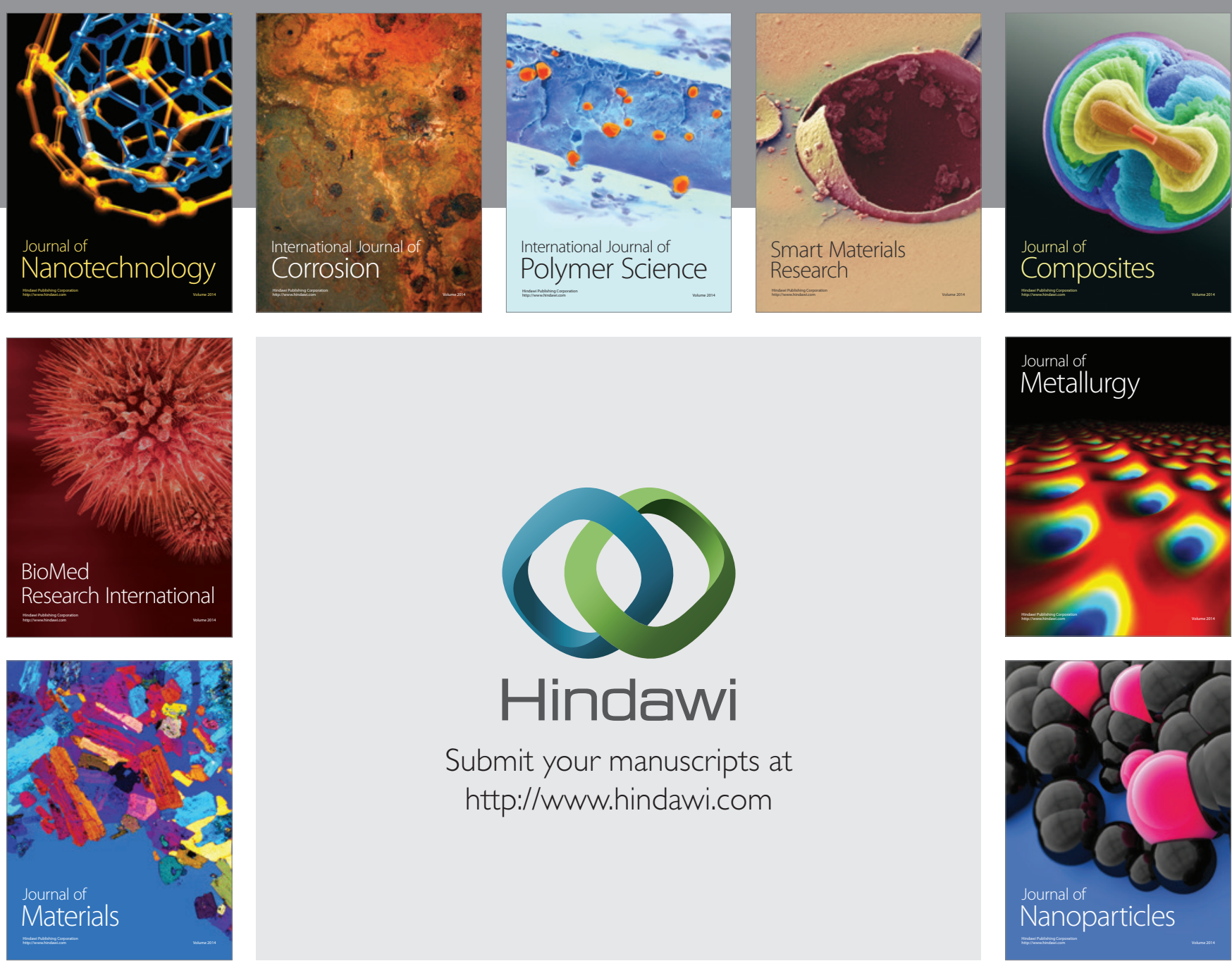

\section{Hindawi}

Submit your manuscripts at

http://www.hindawi.com

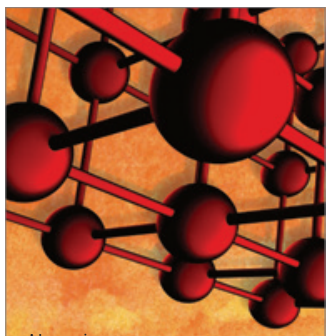

Materials Science and Engineering
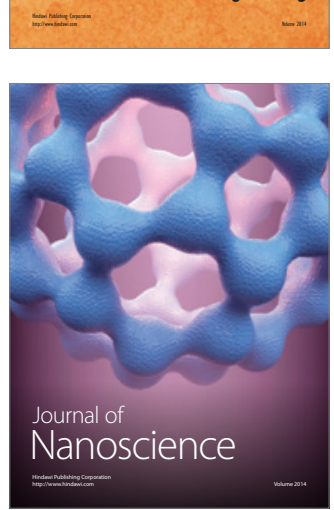
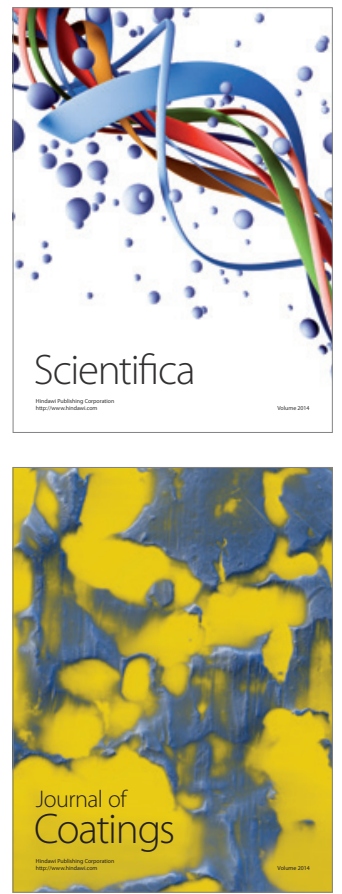
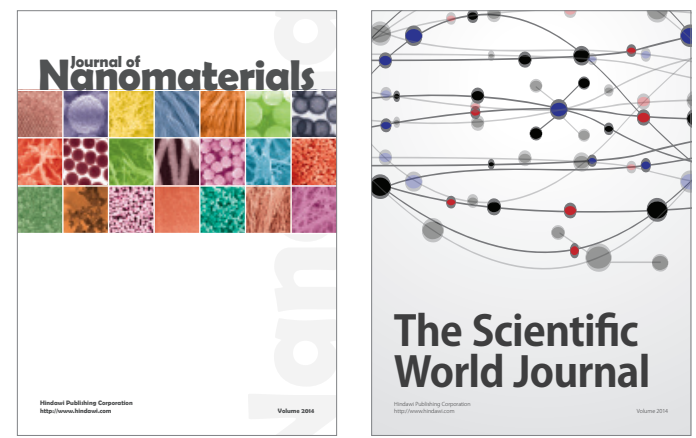

The Scientific World Journal
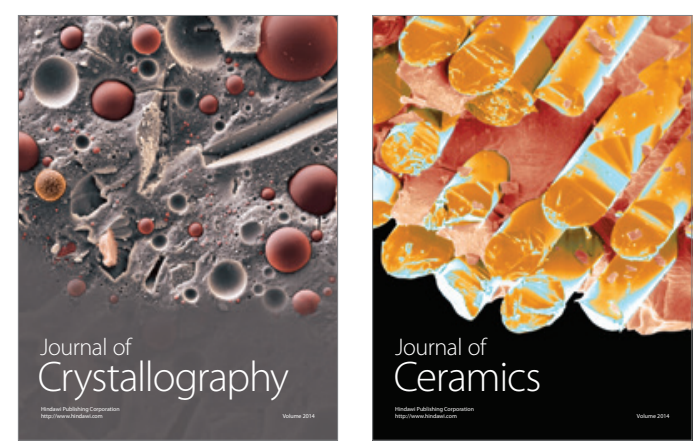
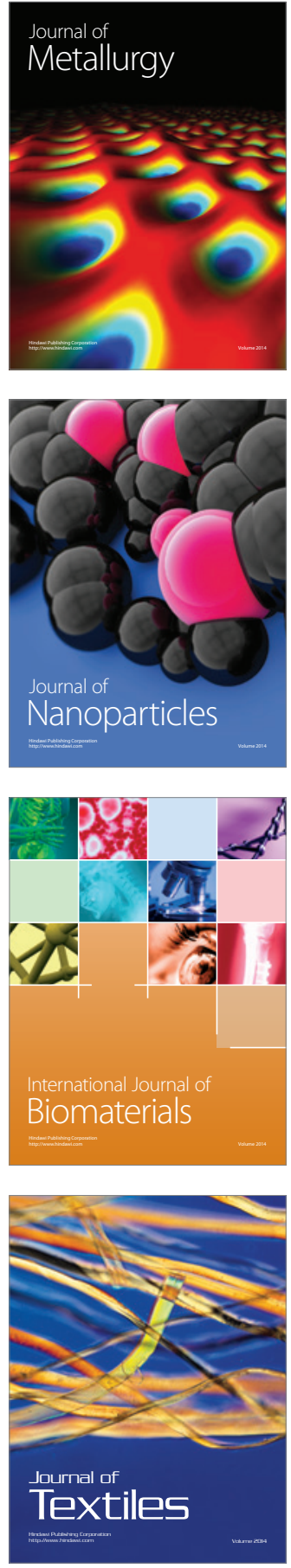